\title{
Patterns and Differentials of Age at First Motherhood Among Married Adolescents in Bangladesh
}

\author{
Md. Abdul Karim ${ }^{1}$, Mohammad Omar Faruk ${ }^{2, *}$ \\ ${ }^{1}$ Department of Statistics, University of Chittagong, Chattogram, Bangladesh \\ ${ }^{2}$ Department of Statistics, Noakhali Science and Technology University, Noakhali, Bangladesh
}

Email address:

omarfaruk.faruk396@gmail.com (M. O. Faruk)

${ }^{*}$ Corresponding author

\section{To cite this article:}

Md. Abdul Karim, Mohammad Omar Faruk. Patterns and Differentials of Age at First Motherhood among Married Adolescents in Bangladesh. Biomedical Sciences. Vol. 7, No. 3, 2021, pp. 86-94. doi: 10.11648/j.bs.20210703.15

Received: August 5, 2021; Accepted: September 18, 2021; Published: September 23, 2021

\begin{abstract}
Background: The focal point of this study is to investigate the current scenario of age at first motherhood among ever married adolescents in Bangladesh because early initiation into childbearing is generally the most important determinant of reproductive span, large family size, and population growth. Methods: The study uses the 2017-18 nationally representative Bangladesh Demographic and Health Survey (BDHS) data. In addition to the descriptive measures, Pearson's Chi-square test and binary logistic regression analysis are employed to determine the significant association and impact of explanatory variables on age at adolescent first motherhood, respectively. Results: The overall mean age at adolescents' first motherhood is $16.34 \pm 1.45$ years, with marked variations by available explanatory variables. The bivariate analysis shows that the variables: current age, respondents' education, place of residence, access to mass media, wealth index, age at first cohabitation, continue studies after marriage, spousal age difference, education, and occupation of husbands are significantly associated with age at adolescents' motherhood. Multivariate binary logistic regression reveals that current age, respondents' education, wealth index, age at first cohabitation, spousal age gap, and husbands' occupation significantly impact the age at first motherhood among adolescents in Bangladesh. Conclusions: This study's results will be helpful for the policymakers to take necessary steps to increase the age at first cohabitation to raise the age of adolescent first motherhood by increasing the literacy rate, minimizing the spousal age difference, and improving the socio-economic conditions for good reproductive health, and further reducing fertility in Bangladesh.
\end{abstract}

Keywords: Teenage, Adolescent, Cohabitation, Body Mass Index, Binary Logistic Regression

\section{Introduction}

Adolescents' age at first cohabitation and motherhood are important components of reproductive span and fertility where marriage is universal. Generally, the period of adolescence encompasses the changeover from childhood to adulthood during the second decade of life. Thus, adolescence is considered in this study as life between childhood and adulthood aged 10 and 19 years. This period is regarded as a critical time in the young person's life [1].

WHO (2020) reported that 10 million teenagers between $15-$ 19 years become pregnant every year across the world [2, 3], and $95 \%$ of all teenage pregnancy occurs in low and middleincome countries [4]. Globally, $11 \%$ of the total birth is given by adolescent mothers, and approximately 12 million teenage girls give birth every year [5], with an estimated 3.9 million having unsafe abortions [3]. The United Nations International Children Fund (UNICEF) reported that one in every fifth child is born by a teenage mother, and $80 \%$ of these adolescent pregnancies occur in third-world countries $[6,7]$. Adolescent pregnancy could pose profuse unfavourable health problems to adolescent mothers, such as the risk of death, pregnancyrelated illness, low birth weight babies, high infant mortality rate, and exposure to sexually transmitted diseases [7]. Almost $70 \%$ of the total adolescents of the world reside in developing countries [8]. There is evidence, for instance, that women who have early first births tend to be poorly educated and have lower income and fewer assets later in life [9]. Worldwide, adolescents suffer from an inconsistent share of early nuptial, 
unsafe abortions, unwanted pregnancies, sexually transmitted infections, infertility, malnutrition and anaemia, and genderbased violence $[10,11]$.

Generally, the first visible outcome of the fertility process is the birth of the first child. Women's first birth may be assumed to be one of the significant events and the most remarkable happening because motherhood signals the beginning of her potential reproductive period and introduces an essential pledge of time and resources [12]. In many countries, postponement of first birth, reflecting in the age at first marriage, has contributed greatly to overall fertility decline [13]. But in traditional societies like Bangladesh, the early age of the first cohabitation and teenage motherhood are common phenomena. In Bangladesh, marriage is universal, and most females cherish the desire to become mothers as early as possible after marriage; less, they should be blamed for being sterile. As a result, a high proportion of females at the teenage stage become mothers in Bangladesh. Currently, Bangladesh is one of the densely populated and the $8^{\text {th }}$ most populous countries in the world. The country has the highest juvenile fertility rate in South Asia. In Bangladesh, $28 \%$ of girls age $15-19$ have begun childbearing; $22 \%$ have given birth, and another $6 \%$ are pregnant with the first child [14]. Although the proportion of women age 15-19 who begun childbearing decreased from $33 \%$ (2004) to $31 \%$ (2014) and $28 \%$ in $2017-18$, a decline of 3 percentage points from 2014, but the prevalence of child marriage and teenage motherhood are still high in Bangladesh. The TFR in Bangladesh is 2.3 children per woman in 2017. The TFR declined from 3.4 (1993-94) to 2.3 (2011) and has since remained static up to 2017 [14]. Although the current fertility rate in Bangladesh is relatively lower than earlier, it is also considered high compared to its area and national resources.

The study on age at first birth among teenagers signifies fertility at the early stage of married life. It is the most welcome event for almost all families in traditional Bangladeshi societies. Moreover, there is little chance of memory lapse in reporting the date of cohabitation and first birth. Therefore, considering the potentially wide-ranging consequences of age at first birth, a detailed examination is made to estimate the age at first birth, its differentials and patterns, and identify the factors influencing the age at first birth among teenage girls in Bangladesh. Nonetheless, it is expected that this analysis will provide a comprehensive picture of age at first motherhood among ever married adolescents in Bangladesh.

\section{Methods}

\subsection{Data}

The data used for this research work is extracted from Bangladesh Demographic and Health Survey 2017-18 (BDHS 2017-18) dataset. The survey was conducted by the National Institute of Population Research and Training (NIPORT) authority, Health Education and Family Welfare Division of the Ministry of Health and Family Welfare under the Training, Research and Development operational plan of $4^{\text {th }}$ HPNSP. Mitra and Associates, located in Dhaka, Bangladesh, implemented the survey. The survey received financial support from the United States Agency for International Development (USAID). The sample for the 2017-18 BDHS is nationally representative, and this survey covers entire inhabitants residing in non-institutional residence units in the country. As part of the international Demographic and Health Surveys Program (MEASURE DHS), the technical support to the BDHS 2017-18 was obtained from the ICF International of Calverton, Maryland, USA.

The BDHS 2017-18 methodology protocols, assessment of biomarkers, and all other instruments connected to the survey were approved by institutional review boards (IRBs) at ICF and the Bangladesh Medical Research Council (BMRC). Before the beginning of data collection activities, the protocols were approved by both IRBs and BMRC. The data for the survey was collected from the respondents only who gave their verbal consent in response to reading out the informed consent declaration by the interviewer.

\subsection{Study Design}

The survey uses a two-stage stratified sampling technique to collect data on the households. In this survey, from 20,376 ever-married females age 15-49 years qualified for interviews, 20,127 were successfully interviewed, produced a response rate of $99 \%$. Among the 20,127 selected females, 1951 were currently under age 20 years. First of all, this cohort was extracted from the large dataset for analysis. Since first birth makes a woman's transition into motherhood, only those women who have had at least one birth are considered to determine the age at first motherhood of the married adolescents in Bangladesh. Therefore, out of 1951 sampled women, 987 are considered in the analysis because they successfully produce at least one birth before three years preceding the survey. A detailed description of the methodology of data collection, including sample design for the survey, can be found elsewhere [14].

\subsection{Statistical Techniques}

At the analytical stage, descriptive measures of age at teenage motherhood have been computed to compare the mean age along with its variability and shape characteristics by available explanatory variables. For this research task, the dependent variable considered here is the age at adolescent first motherhood, and the explanatory variables include: Respondents current age, Religion, Respondents education, Administrative division, Types of place of residence, Ever had a terminated pregnancy, Working status, Access to mass media, Wealth index, BMI, Use of contraception, Age at first cohabitation, Continue study after marriage, Spousal age gap, Husbands education, and occupation. The dependent variable age at first motherhood is dichotomized as "< Median" and " $\geq$ Median" for advance analysis. Moreover, contingency tables were constructed along with 
corresponding Pearson's Chi-square statistics to examine the significant association between age at teenage motherhood and selected background characteristics. Thereafter, multivariate binary logistic regression analysis was employed considering the variables found significant in bivariate analysis to identify the significant factors affecting age at adolescents' motherhood. Finally, to understand the patterns of teenage motherhood at a glance, trend lines have been fitted for age at first cohabitation and birth cohorts with the mean age of motherhood at a different time of points from the nationally representative surveys. The statistical software SPSS (Statistical Package for the Social Science) version 25 is used to conduct the study.

\section{Results}

Early marriage and initiation into childbearing are generally the most important determinants of large family size and population growth. In Bangladesh, early age at first cohabitation and teenage motherhood are common scenarios across the regions. Thus, it is an urgent need to investigate the age at teenage motherhood comprehensively. Therefore, considering the potentiality of wide-ranging consequences of adolescent motherhood, the present study analyses this important demographic variable by selected background characteristics of the respondents. The descriptive statistics of the study variable concerning the selected explanatory variables are presented in Table 1.

Table 1. Descriptive measures of adolescents' age at first motherhood by background characteristics of the respondents.

\begin{tabular}{|c|c|c|c|c|c|c|c|}
\hline \multirow{2}{*}{ Background Characteristics } & \multirow{2}{*}{$\begin{array}{l}\text { Mean age at first } \\
\text { motherhood }\end{array}$} & \multirow{2}{*}{ S. D. } & \multirow[b]{2}{*}{$\gamma_{1}$} & \multirow[b]{2}{*}{$\gamma_{2}$} & \multicolumn{2}{|c|}{$95 \% \mathrm{CI}$} & \multirow{2}{*}{$\begin{array}{l}\text { No. of } \\
\text { respondents }\end{array}$} \\
\hline & & & & & Min & Max & \\
\hline \multicolumn{8}{|l|}{ Current age } \\
\hline $15-17$ & 15.27 & 1.03 & -0.51 & -0.29 & 15.13 & 15.41 & 223 \\
\hline \multicolumn{8}{|l|}{ Religion } \\
\hline Muslim & 16.34 & 1.44 & -0.50 & -0.21 & 16.25 & 16.43 & 922 \\
\hline Others & 16.37 & 1.57 & -0.30 & -0.52 & 15.99 & 16.75 & 65 \\
\hline \multicolumn{8}{|l|}{ Respondents Education } \\
\hline Illiterate & 16.32 & 1.74 & -0.93 & -0.28 & 15.74 & 16.90 & 34 \\
\hline Primary & 16.05 & 1.53 & -0.67 & -0.05 & 15.88 & 16.22 & 310 \\
\hline Secondary and higher & 16.48 & 1.38 & -0.32 & -0.28 & 16.37 & 16.59 & 643 \\
\hline \multicolumn{8}{|l|}{ Division } \\
\hline Barisal & 16.43 & 1.39 & -0.64 & -0.19 & 16.17 & 16.69 & 113 \\
\hline Chittagong & 16.52 & 1.43 & -0.41 & -0.28 & 16.30 & 16.74 & 162 \\
\hline Dhaka & 16.40 & 1.52 & -0.70 & -0.25 & 16.14 & 16.66 & 134 \\
\hline Khulna & 16.31 & 1.48 & -0.26 & -0.26 & 16.05 & 16.57 & 128 \\
\hline Mymensingh & 16.44 & 1.54 & -0.15 & -0.48 & 16.16 & 16.72 & 117 \\
\hline Rangpur & 16.02 & 1.42 & -0.52 & -0.31 & 15.78 & 16.26 & 134 \\
\hline Sylhet & 16.58 & 1.43 & -0.36 & -0.26 & 16.25 & 16.91 & 73 \\
\hline \multicolumn{8}{|l|}{ Type of place of residence } \\
\hline Urban & 16.47 & 1.39 & -0.25 & -0.18 & 16.32 & 16.62 & 308 \\
\hline Rural & 16.28 & 1.48 & -0.60 & -0.24 & 16.17 & 16.39 & 679 \\
\hline \multicolumn{8}{|l|}{ Ever had a terminated pregnancy } \\
\hline No & 16.34 & 1.45 & -0.51 & -0.23 & 16.25 & 16.43 & 921 \\
\hline Yes & 16.30 & 1.44 & -0.04 & -0.30 & 15.95 & 16.65 & 66 \\
\hline \multicolumn{8}{|l|}{ Respondent currently working } \\
\hline No & 16.44 & 1.46 & -0.48 & -0.26 & 16.33 & 16.55 & 700 \\
\hline Yes & 16.08 & 1.40 & -0.48 & -0.21 & 15.92 & 16.24 & 287 \\
\hline \multicolumn{8}{|l|}{ Access to Mass Media } \\
\hline No access & 16.24 & 1.47 & -0.64 & -0.09 & 16.09 & 16.39 & 380 \\
\hline Have access & 16.40 & 1.44 & -0.35 & -0.32 & 16.29 & 16.51 & 607 \\
\hline \multicolumn{8}{|l|}{ Wealth Index } \\
\hline Poor & 16.18 & 1.47 & -0.66 & -0.15 & 16.05 & 16.31 & 479 \\
\hline Middle & 16.47 & 1.45 & -0.39 & -0.21 & 16.27 & 16.67 & 205 \\
\hline Underweight & 16.47 & 1.42 & -0.54 & -0.23 & 16.28 & 16.66 & 225 \\
\hline Normal & 16.29 & 1.45 & -0.47 & -0.20 & 16.18 & 16.40 & 655 \\
\hline Overweight & 16.36 & 1.54 & -0.45 & -0.37 & 16.07 & 16.65 & 107 \\
\hline \multicolumn{8}{|l|}{ Ever use of contraception } \\
\hline No & 16.62 & 1.39 & -0.51 & -0.13 & 16.37 & 16.87 & 122 \\
\hline Yes & 16.30 & 1.46 & -0.50 & -0.24 & 16.20 & 16.40 & 865 \\
\hline Age at first cohabitation & & & & & & & \\
\hline $10-14$ & 15.26 & 1.24 & -0.17 & 0.22 & 15.14 & 15.38 & 412 \\
\hline $15-18$ & 17.11 & 1.05 & -0.58 & -0.03 & 17.02 & 17.20 & 575 \\
\hline Continue study after marriage & & & & & & & \\
\hline No & 16.19 & 1.40 & -0.53 & -0.10 & 16.06 & 16.32 & 458 \\
\hline Yes & 16.47 & 1.48 & -0.38 & -0.36 & 16.34 & 16.60 & 529 \\
\hline Spousal age difference & & & & & & & \\
\hline $0-7$ & 16.53 & 1.45 & -0.35 & -0.37 & 16.40 & 16.66 & 460 \\
\hline $8-14$ & 16.12 & 1.43 & -0.49 & -0.10 & 15.99 & 16.25 & 453 \\
\hline $15-22$ & 16.47 & 1.38 & -0.50 & -0.27 & 16.16 & 16.78 & 74 \\
\hline
\end{tabular}




\begin{tabular}{|c|c|c|c|c|c|c|c|}
\hline \multirow{2}{*}{ Background Characteristics } & \multirow{2}{*}{$\begin{array}{l}\text { Mean age at first } \\
\text { motherhood }\end{array}$} & \multirow{2}{*}{ S. D. } & \multirow[b]{2}{*}{$\gamma_{1}$} & \multirow[b]{2}{*}{$\gamma_{2}$} & \multicolumn{2}{|c|}{$95 \% \mathrm{CI}$} & \multirow{2}{*}{$\begin{array}{l}\text { No. of } \\
\text { respondents }\end{array}$} \\
\hline & & & & & Min & Max & \\
\hline \multicolumn{8}{|l|}{ Husbands education level } \\
\hline Illiterate & 16.00 & 1.56 & -0.49 & -0.16 & 15.73 & 16.27 & 125 \\
\hline Primary & 16.25 & 1.46 & -0.52 & -0.22 & 16.10 & 16.40 & 363 \\
\hline Secondary & 16.38 & 1.39 & -0.50 & -0.12 & 16.24 & 16.52 & 366 \\
\hline Higher & 16.79 & 1.38 & -0.29 & -0.51 & 16.56 & 17.02 & 133 \\
\hline \multicolumn{8}{|l|}{ Husbands Occupation } \\
\hline Agriculture & 16.01 & 1.43 & -0.86 & -0.06 & 15.80 & 16.22 & 170 \\
\hline Service & 16.38 & 1.44 & -0.49 & -0.24 & 16.27 & 16.49 & 612 \\
\hline Business & 16.56 & 1.44 & -0.25 & -0.32 & 16.34 & 16.78 & 170 \\
\hline Others & 16.00 & 1.66 & 0.18 & -0.37 & 15.45 & 16.55 & 35 \\
\hline Bangladesh & 16.34 & 1.45 & -0.23 & -0.49 & 16.25 & 16.43 & 987 \\
\hline Coefficient of Variation (\%) & & & 8.57 & & & & \\
\hline
\end{tabular}

The finding in Table 1 shows that the overall mean age at first motherhood is $16.34 \pm 1.45$ years, which is even one and a half years less than the existing legal age of female marriage (18 years) in Bangladesh. Findings illustrate that the age at first motherhood is heterogeneous, and the shape characteristics of the distribution are negatively skewed $\left(\gamma_{1}=-\right.$ $0.23)$ and platykurtic $\left(\gamma_{2}=-0.49\right)$. Differentials of teenage motherhood elucidate that the lowest mean age at adolescent motherhood $(15.26 \pm 1.24)$ is found among the respondents whose age at first cohabitation is between 12-14 years, followed by respondents whose current age is 15-17 years $(15.27 \pm 1.03)$. On the contrary, the higher mean age at adolescent motherhood is found among the respondents whose age at the first cohabitation is between $15-18$ years (17.11 \pm 1.05$)$, followed by those whose husbands are highly educated $(16.79 \pm 1.38)$. It may be mentioned here that the mean age at first cohabitation is found only $15.44 \pm 1.60$ years, which indicates that age at first cohabitation is less than two and half years than the legal age of female marriage of 18 years in Bangladesh. As expected, the mean age at motherhood is greater for urban adolescents $(16.47 \pm 1.39)$ compared to their vast majority of rural counterparts (16.28.土1.48). Regional differentials reveal that the mean age at teenage motherhood is the highest in Sylhet division (16.58 \pm 1.43$)$ and lowest in Rangpur (16.02 \pm 1.42$)$. Teenage girls who have access to mass media have a relatively higher mean age at motherhood $(16.40 \pm 1.44)$ than those who do not have access to mass media. The respondents who belong to the rich wealth index stratum have a greater mean age at motherhood $(16.49 \pm 1.41)$ than those who belong to other wealth index categories. The underweighted adolescents have maximum mean age at motherhood $(16.47 \pm 1.42)$ in comparison to other BMI groups, probably because of adolescent subfecundity due to malnutrition. Among the variables, the spousal age difference of the adolescent girls is an important variable for the variations of age at first motherhood. Surprisingly, the mean spousal age difference of this study is found $8.40 \pm 3.90$ years. Adolescents with a spousal age difference between 0-7 years take a longer time for their first birth $(16.53 \pm 1.45)$ than adolescents with other categories of spousal age gaps. Besides the descriptive statistics, bivariate analysis is also performed to examine the significant association between teenage motherhood and available background characteristics of the respondents, and the findings are presented in Table 2.

Table 2. Test of association between age at first motherhood and background characteristics of the adolescents, Bangladesh.

\begin{tabular}{|c|c|c|c|c|c|}
\hline \multirow{2}{*}{ Background Characteristics } & \multirow{2}{*}{ Categories } & \multicolumn{2}{|c|}{ Age at first motherhood } & \multirow{2}{*}{ Chi-square } & \multirow{2}{*}{ p-value } \\
\hline & & $12-15$ n (\%) & $16-18$ n (\%) & & \\
\hline \multirow[t]{2}{*}{ Current age } & $15-17$ & $122(12.36)$ & $101(10.23)$ & 99.33 & 0.000 \\
\hline & $18-19$ & $157(15.91)$ & $607(61.50)$ & & \\
\hline \multirow[t]{2}{*}{ Religion } & Muslim & $263(26.65)$ & $659(66.77)$ & 0.458 & 0.499 \\
\hline & Others & $16(1.62)$ & $49(4.96)$ & & \\
\hline \multirow[t]{2}{*}{ Respondents Education } & Illiterate & $12(1.22)$ & $22(2.23)$ & & \\
\hline & Primary & $113(11.45)$ & $197(19.6)$ & 16.98 & 0.000 \\
\hline Secondary and higher & & $154(15.60)$ & $489(49.54)$ & & \\
\hline \multirow[t]{8}{*}{ Division } & Barisal & $32(3.24)$ & $81(8.21)$ & 8.19 & 0.316 \\
\hline & Chittagong & $38(3.85)$ & $124(12.56)$ & & \\
\hline & Dhaka & $40(4.05)$ & $94(9.52)$ & & \\
\hline & Khulna & $36(3.65)$ & $92(9.32$ & 8.19 & 0.316 \\
\hline & Mymensingh & $29(2.94)$ & $88(8.92)$ & & \\
\hline & Rajshahi & $42(4.26)$ & $84(8.51)$ & & \\
\hline & Rangpur & $46(4.66)$ & $88(8.92)$ & & \\
\hline & Sylhet & $16(1.62)$ & $57(5.78)$ & & \\
\hline \multirow{2}{*}{ Type of place of residence } & Urban & $76(7.70)$ & $232(23.51)$ & 2.85 & 0.091 \\
\hline & Rural & $203(20.57)$ & $476(48.23)$ & & \\
\hline \multirow{2}{*}{ Ever had a terminated pregnancy } & No & $262(26.55)$ & $659(66.77)$ & 0.22 & 0.639 \\
\hline & Yes & $17(1.72)$ & $49(4.96)$ & & \\
\hline \multirow{2}{*}{ Respondent currently working } & No & $188(19.05)$ & $512(51.87)$ & 2.36 & 0.124 \\
\hline & Yes & $91(9.22)$ & $196(19.86)$ & & \\
\hline \multirow[t]{2}{*}{ Access to Mass Media } & No & $120(12.16)$ & $260(26.34)$ & 3.34 & 0.068 \\
\hline & Yes & $159(16.11)$ & $448(45.39)$ & & \\
\hline
\end{tabular}




\begin{tabular}{|c|c|c|c|c|c|}
\hline \multirow{2}{*}{ Background Characteristics } & \multirow{2}{*}{ Categories } & \multicolumn{2}{|c|}{ Age at first motherhood } & \multirow{2}{*}{ Chi-square } & \multirow{2}{*}{ p-value } \\
\hline & & $12-15$ n (\%) & $16-18$ n (\%) & & \\
\hline \multirow{3}{*}{ Wealth Index } & Poor & $156(15.81)$ & $323(32.73)$ & & \\
\hline & Middle & $48(4.86)$ & $157(15.91)$ & 8.60 & 0.014 \\
\hline & Rich & $75(7.60)$ & $228(23.10)$ & & \\
\hline \multirow{3}{*}{ Body Mass Index } & Underweight & $61(6.18)$ & $164(16.62)$ & 0.30 & 0.863 \\
\hline & Normal & $186(18.84)$ & $469(47.52)$ & & \\
\hline & Overweight & $32(3.24)$ & $75(7.60)$ & & \\
\hline \multirow[t]{2}{*}{ Ever use of contraception } & No & $28(2.84)$ & $94(9.52)$ & 1.94 & 0.164 \\
\hline & Yes & $251(25.43)$ & $614(62.21)$ & & \\
\hline \multirow[t]{2}{*}{ Age at first cohabitation } & $10-14$ & $245(24.82)$ & $167(16.92)$ & 339.48 & 0.000 \\
\hline & $15-18$ & $34(3.44)$ & $541(54.81)$ & & \\
\hline \multirow{2}{*}{ Continue study after marriage } & No & 145 (14.69) & $313(31.71)$ & 4.85 & 0.028 \\
\hline & Yes & $134(13.58)$ & $395(40.02)$ & & \\
\hline \multirow[t]{3}{*}{ Spousal age difference } & $0-7$ & $110(11.14)$ & $350(35.46)$ & 9.14 & 0.010 \\
\hline & $8-14$ & $149(15.10)$ & $304(30.80)$ & & \\
\hline & $15-22$ & $20(2.03)$ & $54(5.47)$ & & \\
\hline \multirow[t]{4}{*}{ Husbands' education } & Illiterate & $46(4.66)$ & $79(8.00)$ & $10.927 \mathrm{a}$ & 0.012 \\
\hline & Primary & $108(10.94)$ & $255(25.84)$ & & \\
\hline & Secondary & $100(10.13)$ & $266(26.95)$ & & \\
\hline & Higher & $25(2.53)$ & $108(10.94)$ & & \\
\hline \multirow[t]{4}{*}{ Husbands' occupation } & Agriculture & $63(6.38)$ & $107(10.84)$ & & \\
\hline & Service & $169(17.12)$ & $443(44.88)$ & 12.18 & 0.007 \\
\hline & Business & $35(3.55)$ & $135(13.68)$ & & \\
\hline & Others & $12(1.22)$ & $23(2.33)$ & & \\
\hline
\end{tabular}

The results in Table 2 show that the respondents' current age is highly significantly associated with the age at adolescents' first motherhood $(\mathrm{p}<0.05)$ and a maximum of the adolescents $(n=607,61.50 \%)$ aged $18-19$ who give birth at age 16-18 years. The respondents' education is one of the most significant factors $(p<0.05)$ associated with the age of adolescent motherhood. The highest number of the adolescents with secondary and higher education $(n=489$, $49.54 \%$ ) became mother at age 16-18 years compared to other categories of the educational status. Like education, wealth index $(p<0.05)$ and access to mass media $(p<0.10)$ are also significantly associated with the age at adolescent motherhood. Age at first cohabitation $(p<0.05)$ and spousal age difference $(\mathrm{p}<0.05)$ found to have a highly significant association with the age at motherhood of the adolescents. The respondents who continue study after marriage $(n=395$,
$40.02 \%$ ) become a mother at age 16-18 years, and the variable is also associated with the age of adolescent motherhood $(\mathrm{p}<0.05)$. Husbands' education and occupation also play a vital role in varying teenage motherhood. The results in Table 2 also depict that husband education $(\mathrm{p}<0.05)$ and occupation $(p<0.05)$ show a significant association with the age at adolescent motherhood.

In addition to univariate and bivariate analyses, multivariate binary logistic regression analysis is also used in this study to identify the risk factors of adolescent motherhood. For this purpose, the age at first adolescent motherhood has dichotomized as the value zero for age at first motherhood less than 16 years (median) and 1 for age 16 years and above. Table 3 present the estimates of logistic regression of the different covariates of age at first motherhood.

Table 3. Logistic regression coefficients and odds ratios of the selected factors associated with age at first motherhood, Bangladesh.

\begin{tabular}{|c|c|c|c|c|c|c|}
\hline \multirow{2}{*}{ Background Characteristics } & \multirow{2}{*}{ B } & \multirow{2}{*}{ S. E. } & \multirow{2}{*}{ p-value } & \multirow{2}{*}{ Odds Ratio } & \multicolumn{2}{|c|}{ 95\% CI Odds } \\
\hline & & & & & Lower & Upper \\
\hline \multicolumn{7}{|l|}{ Current age } \\
\hline $15-17 *$ & & & & 1 & & \\
\hline $18-19$ & 1.10 & 0.21 & 0.000 & 3.02 & 2.021 & 4.506 \\
\hline \multicolumn{7}{|l|}{ Res. education } \\
\hline Illiterate* & & & 0.011 & 1 & & \\
\hline Primary & 0.20 & 0.51 & 0.701 & 1.22 & 0.447 & 3.306 \\
\hline Secondary and higher & 0.85 & 0.52 & 0.105 & 2.33 & 0.838 & 6.488 \\
\hline \multicolumn{7}{|l|}{ Place of residence } \\
\hline Urban* & & & & 1 & & \\
\hline Rural & -0.22 & 0.22 & 0.313 & 0.80 & 0.517 & 1.235 \\
\hline \multicolumn{7}{|l|}{ Access to Mass Media } \\
\hline No* & & & & 1 & & \\
\hline Yes & 0.28 & 0.21 & 0.177 & 1.33 & 0.88 & 2.004 \\
\hline \multicolumn{7}{|l|}{ Wealth Index } \\
\hline Poor* & & & 0.095 & 1 & & \\
\hline Middle & 0.31 & 0.26 & 0.220 & 1.37 & 0.829 & 2.261 \\
\hline Rich & -0.30 & 0.26 & 0.253 & 0.74 & 0.445 & 1.238 \\
\hline
\end{tabular}




\begin{tabular}{|c|c|c|c|c|c|c|}
\hline \multirow{2}{*}{ Background Characteristics } & \multirow{2}{*}{ B } & \multirow{2}{*}{ S. E. } & \multirow{2}{*}{ p-value } & \multirow{2}{*}{ Odds Ratio } & \multicolumn{2}{|c|}{ 95\% CI Odds } \\
\hline & & & & & Lower & Upper \\
\hline $10-14 *$ & & & & 1 & & \\
\hline $15-18$ & 3.02 & 0.21 & 0.000 & 20.56 & 13.497 & 31.306 \\
\hline \multicolumn{7}{|l|}{ Continue study after marriage } \\
\hline No* & & & & 1 & & \\
\hline Yes & 0.21 & 0.21 & 0.316 & 1.23 & 0.821 & 1.839 \\
\hline Spousal age difference & & & 0.157 & & & \\
\hline$<8^{*}$ & & & & 1 & & \\
\hline $8-14$ & -0.38 & 0.20 & 0.055 & 0.686 & 0.467 & 1.007 \\
\hline$>14$ & -0.26 & 0.37 & 0.484 & 0.772 & 0.374 & 1.593 \\
\hline \multicolumn{7}{|l|}{ Husbands' education } \\
\hline Illiterate* & & & 0.68 & & & \\
\hline Primary & 0.22 & 0.32 & 0.49 & 1.245 & 0.669 & 2.314 \\
\hline Secondary & 0.31 & 0.33 & 0.338 & 1.369 & 0.72 & 2.602 \\
\hline Higher & 0.5 & 0.42 & 0.238 & 1.648 & 0.719 & 3.779 \\
\hline \multicolumn{7}{|l|}{ Husbands' occupation } \\
\hline Agriculture* & & & 0.227 & & & \\
\hline Service & 0.15 & 0.25 & 0.543 & 1.162 & 0.717 & 1.883 \\
\hline Business & 0.64 & 0.33 & 0.05 & 1.891 & 1.001 & 3.573 \\
\hline Others & 0.22 & 0.54 & 0.683 & 1.246 & 0.433 & 3.584 \\
\hline Constant & -2.07 & 0.67 & 0.002 & 0.126 & & \\
\hline * Reference Category & & & & & & \\
\hline
\end{tabular}

The findings in Table 3 reveal that respondents' current age has a significant impact on the age at first motherhood $(\mathrm{p}<0.05)$. The respondents' age group 18-19 years has a higher (OR: 3.02, 95\% CI: 2.02-4.51) probability of giving birth at median age and above than the respondents aged less than the median (16 years). The educational levels of the adolescents also significantly influence the age at motherhood $(p<0.05)$. The result in Table 3 illustrates that the respondents who are secondary and higher educated have 2.33 times (95\% CI: 0.84-6.49) higher likelihood of taking a long time to be a mother compared to their illiterate counterparts. The wealth index has a significant impact on the age at adolescents motherhood $(\mathrm{p}<0.1)$. The respondents who belong to the middle class have more probability of becoming late motherhood (OR: $1.37,95 \%$ CI: 0.83-2.26) than other wealth index categories. As expected, age at first cohabitation significantly impacts the age at adolescents' motherhood $(\mathrm{p}<0.05)$. The adolescents whose age at first cohabitation are in the age group 15-18 years are 20.56 times (95\% CI: 13.50-31.31) higher odds of late motherhood than the respondents whose age at first cohabitation is $12-14$ years.
Biological maturity may be the leading cause of late motherhood in the age group 15-18 years. The spousal age difference is an important factor in the variation of demographic events because the difference between brides and grooms is noticeably higher among adolescents in Bangladesh. It can be seen from Table 3 that the spousal age difference is also considered to be a significant determinant that affects adolescents' motherhood $(\mathrm{p}<0.1)$. The lower spousal age difference ( $<8$ years) has higher odds of giving late birth than other groups of the spousal age differences. Husbands occupations of the respondents significantly influence the age at adolescents motherhood $(\mathrm{p}<0.05)$. Adolescents whose husbands' occupation is business are more likely to give birth later than other occupational groups (OR: 1.89, 95\% CI: 1.00-3.57). The Hosmer and Lemeshow test of goodness of fit illustrates that the binary logistic regression model fits the data well (Chi-square: 2.423 , pvalue: 0.965). In addition to multidimensional numerical findings of age at first adolescent motherhood, Figure 1 displays the same to understand the trends at a momentary look based on age at first cohabitation and birth cohorts.
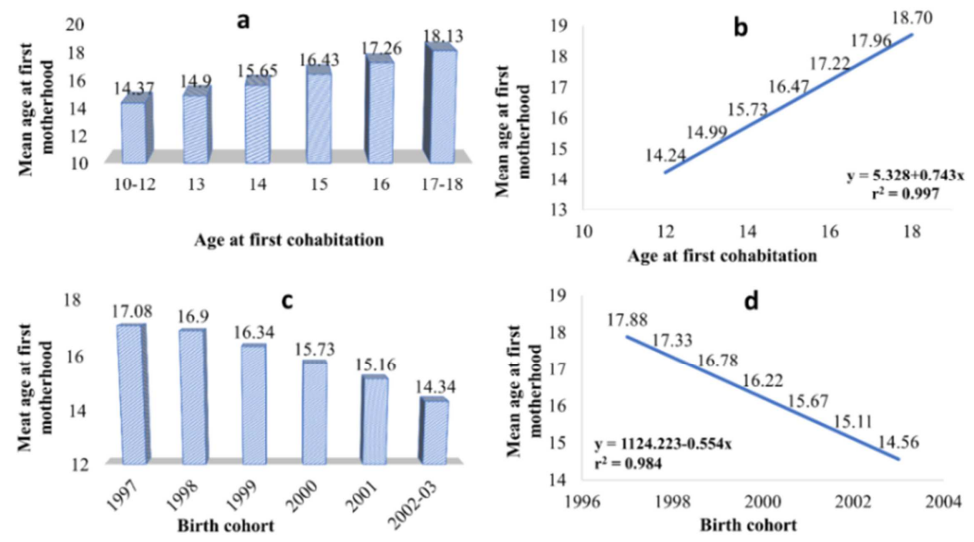

Figure 1. Trends of age at first adolescent motherhood with respect to age at first cohabitation and birth cohorts. 
Figure 1a illustrates that the mean age at first motherhood and age at first cohabitation are highly positively correlated, indicating that with the increase in age at first cohabitation, the mean age of adolescent motherhood also increases. The trend line (Figure 1b.) shows a sharp rise in the age of motherhood with the increase of age at first cohabitation. The estimate of the trend line $(b=0.743)$ indicates that for a oneyear increase in the age of the first cohabitation, the age at adolescent motherhood also increases by, on average, about nine months. Similarly, Figure 1 (c, d) portray the inverse relationship between mean age at first motherhood and birth cohorts of teenage girls. In Figure $1 \mathrm{~d}$, the coefficient $(b=-$ $0.554)$ reflects a sharp decrease in age at adolescents' first

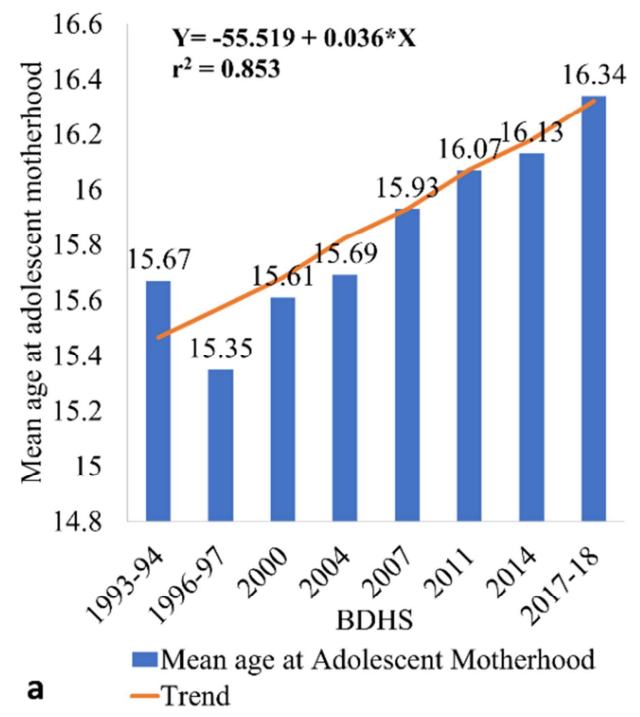

motherhood from old birth cohort to recent birth cohort. The mean age at first motherhood among the recent birth cohorts is relatively lower because the more fertile teenage girls are included in this cohort. In addition to trends of mean age at adolescent motherhood based on age at first cohabitation and birth cohorts of the respondents, Figure 2a also depicts the trend of mean age at first motherhood during the period 1993-2018 to understand the patterns at a glance. Since age at first cohabitation is highly positively correlated with the age at first motherhood, therefore Figure $2 \mathrm{~b}$ presents the trend of mean age at first cohabitation during the same period to observe the comparative patterns of mean age at adolescent first motherhood.

Figure 2. Trends of mean age at adolescent motherhood and cohabitation during the period 1993-2018.

Figure 2 (a, b) shows that both mean age adolescent motherhood and mean age at first cohabitation have an increasing trend during the periods mentioned above. Figure 2a shows that adolescents' motherhood mean age increment rate is 0.03 years for every four years. The value of the estimate in Figure $2 a(b=0.036)$ reflects that the mean age at motherhood increases by about three months for every four years. Similarly, Figure $2 \mathrm{~b}$ indicates the increasing trend of age at first cohabitation during the same periods. The estimate $(b=0.071)$ shows that the mean age at first cohabitation among teenagers also increases to about six months for every four years in Bangladesh.

\section{Discussion}

Adolescent motherhood is a global health concern due to its high prevalence in low-and middle-income countries. Adolescent motherhood jeopardizes an ultimate and efficacious changeover to adulthood [6]. Moreover, teenage mothers are more at risk of significant malformation compared to adult mothers [15]. From earlier studies, there is ample evidence that several socio-economic and demographic factors contribute to teenage motherhood between 15-19 years, and this study aims to determine such features affecting it. This study gives clear information that entrances into the childbearing of Bangladeshi adolescents are too early. This study found a significant relationship between the current age of the respondents and age at first adolescents motherhood and the adolescents belong to comparatively higher age group give late birth than their low age counterparts. A study conducted in Ethiopia also found a significant association between teenage motherhood and the age of the respondents $[16,17]$ and higher teenage childbearing is observed among the adolescent age group 1819 years $[18,19]$. As expected, adolescents' education plays a significant role to avert child motherhood in a great magnitude. The illiterate respondents have a greater risk of early motherhood than adolescents with secondary and higher education. Teenage motherhood is highly significantly influenced by the educational status of the respondents [17, 19-21], and illiterate adolescents are more susceptible to give early birth [22-24]. The graduate students have a lower probability of getting early motherhood than secondary and illiterate respondents [25-28]. The wealth index, a proxy of income, is a significant determinant of adolescent motherhood, and middle-class adolescents have higher mean 
age at motherhood than other wealth indices of the respondents. A similar result was found in a study that a lower wealth index is a risk factor that significantly affects teenage pregnancy [29]. Moreover, the richest wealth index adolescents are less likely to be early pregnant compared to the poorest wealth quantile [22]. This study found a significant impact of age at first cohabitation on the age at adolescent motherhood. The respondents whose age at first cohabitation is between 10-14 years are at risk of early motherhood than the cohabitation age group 15-18 years. A previous study in Bangladesh found a significant influence of early marriage on age at first adolescents motherhood, and they are more likely to be early motherhood than the adolescent with late marriage [25]. The spousal age gap is a significant predictor that influences teenage motherhood. The spousal age gap of fewer than eight years has a higher likelihood of late motherhood, while the spousal age difference greater than eight years are more at risk of early motherhood. A significant impact is identified between spousal age difference and adolescent motherhood, and a lower spousal age gap is associated with a lower chance of early adolescent motherhood [22]. Husbands occupation of the respondents has a substantial impact on adolescent motherhood, and the respondents whose husbands occupation is business are more susceptible to be late motherhood than other husbands occupational status in Bangladesh.

\section{Conclusion}

Generally, childbearing at early age entails substantial death risks for both mother and the child. Pregnancy at the teenage stage includes anemia, low birth weight babies, stillbirth, high infant mortality, high maternal mortality, malnutrition, large population size, and population growth. Moreover, to be the extent that early first birth is associated with poor educational and employment opportunities and more rapid childbearing. In addition, reproductive span is lengthened due to early access into childbearing, which accelerates fertility. The finding of this research study confirms that the mean age at adolescents motherhood in Bangladesh is extremely lower, although its fertility rate is still so far above replacement level. The results of this study reflect that the secondary and higher educated adolescents take more time to give their first birth than other educational status groups. Similarly, higher age at first cohabitation and lower spousal age difference also significantly impact the age of teenage motherhood. Moreover, the husbands' occupation of the respondents has a remarkable impact on the age at first motherhood of the adolescents. Therefore, it can be concluded that the study's results help the policymakers initiate appropriate policies to reduce the frequency of teenage motherhood by properly addressing the abovementioned issues in Bangladesh.

\section{Abbreviations}

BMI: Body Mass Index.
BDHS: Bangladesh Demogrpahic and Health Survey

$<$ : Less than

$\geq$ : Greater than equal

UNICEF: The United Nations International Children Fund

NIPORT: National Institute of Population Research and Training

USAID: United States Agency for International Development

HPNSP: The Health Sector and Fourth Health Population and Nutrition Sector Programmes

\section{Declarations}

\section{Ethics Statements and Consent for Publication}

As part of the international Demographic and Health Surveys Program (MEASURE DHS), the technical support to the BDHS 2017-18 was obtained from the ICF International of Calverton, Maryland, USA. The respondents give their verbal consent to read out the informed consent statement by the interrogator. The user instructions were firmly followed, and permission of the BDHS dataset was accessible from https://dhsprogram.com/data. The ethical approval for the BDHS 2017-18 was taken by NIPORT from the BMRC (Bangladesh Medical Research Council).

\section{Declaration of Competing Interest}

The authors declare that there is no competing interest in this research.

\section{Funding}

This research did not get funds from any academic or business organization.

\section{Acknowledgements}

We acknowledge the Measure DHS (Demographic and Health Surveys) Data Archive, ICF International, USA for access to all the seven rounds of the Bangladesh Demographic and Health Survey (1993-2018) data.

\section{Appendix}

Supplementary data Supplementary data to this article can
found
https://data.mendeley.com/datasets/tn9pvppxx2/draft?a=03d2
15aa-6d19-4643-8c12-f6d4d7241600.

\section{References}

[1] Ngum Chi Watts MC, Liamputtong P, McMichael C. Early motherhood: A qualitative study exploring the experiences of African Australian teenage mothers in greater Melbourne, Australia. BMC Public Health [Internet]. BioMed Central Ltd. 2015 [cited 2021 Jun 15]; 15. Available from: https://pubmed.ncbi.nlm.nih.gov/26358465/. 
[2] Darroch JE, Woog V, Bankole A. ADDING IT UP: Costs and Benefits of Meeting the Contraceptive Needs of Adolescents. New York Guttmacher Inst. 2016; 1-16.

[3] Adolescent pregnancy [Internet]. [cited 2021 Jun 16]. Available from: https:/www.who.int/news-room/factsheets/detail/adolescent-pregnancy.

[4] Early marriages, adolescent and young pregnancies Report by the Secretariat. 2012

[5] Ghose S, John LB. Adolescent pregnancy: an overview. Int J Reprod Contraception, Obstet Gynecol. Medip Academy; 2017; 6: 4197.

[6] GIRLHOOD, NOT MOTHERHOOD Preventing Adolescent Pregnancy [Internet]. 2015 [cited 2021 Jun 6]. Available from: www.unfpa.org.

[7] Odejimi O, Bellingham-Young D, Dr B, Bellingham-YoungD. Teenage pregnancy in Africa: Trend and Determinants in the 21 st Century. J Heal Soc Care Improv. 2016; 1: 12-20.

[8] Moyosore A. Influence of Socio-demographic Factors on Adolescent's Sexual and Reproductive Health and Behaviour. Asian J Med Heal [Internet]. Sciencedomain International; 2016 [cited 2021 Jun 16]; 1: 1-10. Available from: https://www.journalajmah.com/index.php/AJMAH/article/vie $\mathrm{w} / 15638$.

[9] Gyimah SO. PSC Discussion Papers Series Women' $s$ Educational Attainment and the Timing of Parenthood in Ghana: A Cohort Perspective. 17.

[10] Neema S, Musisi N, Kibombo R. Adolescent Sexual and Reproductive Health in Uganda: A Synthesis of Research Evidence [Internet]. 2004. Available from: www.guttmacher.org.

[11] Brahmbhatt H, Kågesten A, Emerson M, Decker MR, Olumide AO, Ojengbede O, et al. Prevalence and determinants of adolescent pregnancy in urban disadvantaged settings across five cities. J Adolesc Heal [Internet]. Elsevier Inc.; 2014; 55: S48-57. Available from: http://dx.doi.org/10.1016/j.jadohealth.2014.07.023.

[12] Lapierre-Adamcyk E, Rao KV. Age at first birth and lifetime fertility. J Biosoc Sci [Internet]. J Biosoc Sci; 1988 [cited 2021 Jun 16]; 20: 167-74. Available from: https://pubmed.ncbi.nlm.nih.gov/3384833/.

[13] Bangladesh HS. Bangladesh Demographic and Health Survey. 1999.

[14] National Institute of Population Research and Training (NIPORT), ICF International. Bangladesh demographic and health survey 2017-18. 2020; 1-511.

[15] Gurung R, Målqvist M, Hong Z, Poudel PG, Sunny AK, Sharma S, et al. The burden of adolescent motherhood and health consequences in Nepal. BMC Pregnancy Childbirth. BMC Pregnancy and Childbirth; 2020; 20: 1-7.

[16] Habitu YA, Yalew A, Bisetegn TA. Prevalence and factors associated with teenage pregnancy, northeast Ethiopia, 2017 : A cross-sectional study. J Pregnancy. 2018; 2018.

[17] Rindfuss RR, John C St. Social Determinants of Age at First Birth. J Marriage Fam. 1983; 45: 553.

[18] Kassa GM, Arowojolu AO, Odukogbe ATA, Yalew AW. Trends and determinants of teenage childbearing in Ethiopia: Evidence from the 2000 to 2016 demographic and health surveys. Ital J Pediatr. Italian Journal of Pediatrics; 2019; 45: $1-13$.

[19] Alemayehu T, Haider J, Habte D. Determinants of adolescent fertility in Ethiopia. Ethiop J Heal Dev. 2010; 24: 30-8.

[20] Ziblim S-D, Yidana A, Mohammed A-R. Determinants of Antenatal Care Utilization among Adolescent Mothers in the Yendi Municipality of Northern Region, Ghana. Ghana J Geogr [Internet]. 2018; 10: 78-97. Available from: https://dx.doi.org/10.4314/gjg.v10i1.5.

[21] Raj AD, Rabi B, Amudha P, van Teijlingen Edwin R, Glyn C. Factors associated with teenage pregnancy in South Asia: A systematic review. Heal Sci J. 2010; 4: 3-14.

[22] Islam MM, Islam MK, Hasan MS, Hossain MB. Adolescent motherhood in Bangladesh: Trends and determinants. PLoS One. $2017 ; 12$ : 1-14.

[23] Mezmur H, Assefa N, Alemayehu T. Teenage pregnancy and its associated factors in eastern ethiopia: A community-based study. Int J Womens Health. 2021; 13: 267-78.

[24] Vincent G, Alemu FM. Factors contributing to, and effects of, teenage pregnancy in Juba. Factors Contrib to, Eff of, teenage pregnancy Juba. 2016; 9: 28-31.

[25] Ali M, Alauddin S, Khatun MF, Maniruzzaman M, Islam SMS Determinants of early age of mother at first birth in Bangladesh: a statistical analysis using a two-level multiple logistic regression model. J Public Heal. Journal of Public Health; 2020.

[26] Nahar MZ, Zahangir MS. Patterns and Determinants of Age At First Birth in Bangladesh. Turkish J Popul Stud. 2013; 35: $63-77$.

[27] Fayed AA, Wahabi H, Mamdouh H, Kotb R, Esmaeil S. Demographic profile and pregnancy outcomes of adolescents and older mothers in Saudi Arabia: Analysis from Riyadh Mother (RAHMA) and Baby cohort study. BMJ Open. 2017; 7: $1-11$.

[28] Govender D, Naidoo S, Taylor M. Prevalence and Risk Factors of Repeat Pregnancy among South African Adolescent Females. Afr J Reprod Health. 2019; 23: 73-87.

[29] Sarder M, Alauddin S, Ahammed B. Determinants of teenage marital pregnancy among bangladeshi women: An analysis by the cox proportional hazard model. Soc Heal Behav [Internet]. Medknow; 2020 [cited 2021 Jun 7]; 3: 137. Available from: https://www.shbonweb.com/article.asp?issn=25899767 ; year $=2020 ;$ volume $=3 ;$ issue $=4 ;$ spage $=137$; epage $=143$; aul ast $=$ Sarder. 